\title{
Fe (III)-Based Ammonia-Free Bath for Electrodeposition of Fe-W Alloys
}

\author{
$\underline{\text { A. Nicolenco }}, \underline{\text { N. Tsyntsaru }}, \underline{a, b}, \underline{z}$ and $\underline{\text { H. Cesiulis }}{ }^{a}$
}

aDepartment of Physical Chemistry, Vilnius University, Vilnius LT-03225, Lithuania

IInstitute of Applied Physics of ASM, Chisinau, MD - 2028, Moldova

\begin{abstract}
Electrodeposited Fe-W alloys are the subject of extensive studies to be applied in versatile engineering applications, and many solutions based on $\mathrm{Fe}$ (II) complexes are described for their deposition. However, in aqueous solutions containing dissolved oxygen, $\mathrm{Fe}$ (II) compounds are unstable thermodynamically and tend to oxidize to $\mathrm{Fe}$ (III) state that decreases the sustainability of the baths. The aim of the present study was to develop an environment-friendly and thermodynamically stable $\mathrm{Fe}$ (III)-based electrolyte for electrodeposition of Fe-W alloys with tunable composition. It was found that: (i) concurrent use of two complexing agents as citric and glycolic acids stabilizes $\mathrm{Fe}(\mathrm{III})$-based bath in neutral and weak alkaline medium (no precipitates are formed); (ii) the current efficiency of the process can reach up to $60-70 \%$, which has never been reported before for Fe-W alloys electrodeposition; (iii) nanocrystalline Fe-W coatings containing 11-24 at.\% of W can be obtained from $\mathrm{Fe}(\mathrm{III})$-based glycolate-citrate bath at temperature range $20-65^{\circ} \mathrm{C}$. The increase in tungsten content in the alloy resulted in decreased grain size up to $<5 \mathrm{~nm}$; (iv) smooth, free of cracks and having deposition rates up to $0.18 \mu \mathrm{m} / \mathrm{cm}^{1}$ alloys are successfully electrodeposited at elevated temperatures from elaborated glycolate-citrate electrolyte.
\end{abstract}

The rapid development of modern technologies in the chemical engineering requires obtaining of new materials with tunable composition, microstructure, and properties. Electrodeposited tungsten alloys with $\mathrm{Fe}, \mathrm{Co}$ and $\mathrm{Ni}$ attracted much attention as alternative for electrolytic chromium replacement 1 ? 2 produced from the bath based on highly toxic $\mathrm{Cr}(\mathrm{VI})$. Recently, the increased interest is particularly focused on the electrodeposition of Fe-W alloys including for such emerging applications as production of lithium ion batteries, $\underline{3}$ recording media, $\underline{\underline{4}}$ catalyst $\underline{\underline{5}}$ and fuel cells. $\underline{6}$

Nevertheless, that the electrodeposition of Fe-W alloys is actively studied since $1940 \mathrm{~s}, \underline{z}$ the development and optimization of new electrolytes are still highly demanded. Thus, citrate baths were extensively investigated $\underline{-11}$ for Fe-W alloys electrodeposition. Also, ammonia was usually added to the electrolytes for alloys deposition as it increases the solubility of metal's complexes and influences on the species distribution, 12 13 and has a significant effect on W co-deposition and bath stability. Such citrate-ammonia electrolytes enable to produce rather smooth and silvery to gray in appearance Fe-W coatings, 4.14 but the performance of those electrolytes is significantly affected by competing reactions of hydrolysis and complexing.10 Thus, in order to deposit reach in tungsten (up to 30-35 at.\%) Fe-W alloys from citrate-ammonia baths the optimum values of $\mathrm{pH} 7.0-8.5$ should be used.15 Nevertheless, in order to reduce the environmental impact of electrochemical bath containing ammonia salts, attempts to find ammonia-free baths were explored.1.16 19 An example of successful elaboration of ammonia-free baths was demonstrated for $\mathrm{Ni}$ alloys electrodeposition, $\underline{20} \underline{21}$ where electrolytes based on glycolic acid were used, but there are no similar data reported for Fe-W alloys deposition.

At this point it is worth to note, that the chemical stability is an important characteristic of electroplating baths especially for ones used for iron alloys electrodeposition $\underline{22} \underline{2} \underline{2}$ that complicates bath maintenance. 
The standard potential for oxygen reduction is more positive than for $\mathrm{Fe}^{3+}$ reduction to $\mathrm{Fe}^{2+}$, hence the spontaneous reaction in the presence of dissolved oxygen occurs:

$$
4 \mathrm{Fe}^{2+}+\mathrm{O}_{2}+4 \mathrm{H}^{+}=4 \mathrm{Fe}^{3+}+2 \mathrm{H}_{2} \mathrm{O}
$$

The value of $K_{\text {eq }}$ for this reaction can be estimated based on the tabulated data of standard reduction potentials and using the well-known relationship between standard cell potential $\left(\Delta E^{o}\right)$ and equilibrium constant $\left(K_{\text {eq }}\right)$ :

$$
\Delta E^{0}=\frac{R T}{n F} \ln K_{e q}
$$

It was found that $K_{\text {eq }}$ is big as $1.3 \cdot 10 .{ }^{31}$ This result means that practically total amount of $\mathrm{Fe}^{2+}$ eventually will oxidize to $\mathrm{Fe}^{3+}$ irrespectively on the complexation of iron ions. Thus, electrolytes based on $\mathrm{Fe}$ (II) salts are unstable thermodynamically and the solution content is governed by the $\mathrm{Fe}$ (II) oxidation kinetics. It was shown $\underline{24} \underline{25}$ that mentioned above citrates and ammonia inhibit the kinetics of $\mathrm{Fe}$ (II) oxidation to $\mathrm{Fe}(\mathrm{III})$, but cannot prevent it. Some attempts were made to prolong bath life by adding reducing agents, $\underline{2} \underline{2} \underline{2}$ but those compounds can affect the bath maintenance and coatings properties. In this view, it should be reasonable to use electrolytes based on Fe(III) salts to avoid oxidation of $\mathrm{Fe}$ (II) species. Nevertheless, study on the electrodeposition of Fe-W alloys from $\mathrm{Fe}$ (III) solutions is rather limited. The reason is that the current efficiency and tungsten content are significantly lower for alloys obtained from $\mathrm{Fe}$ (III) in comparison to $\mathrm{Fe}$ (II) studied electrolytes.12.14.25.29 Howbeit, it is worth to mention, that the straight comparison of $\mathrm{Fe}$ (II) and $\mathrm{Fe}$ (III)-based solutions operating at the same conditions remains poorly explored. Therefore, the aim of this study is to explore the new sustainable electrolytic bath based on $\mathrm{Fe}$ (III) salt as an alternative to conventional $\mathrm{Fe}(\mathrm{II})$-based bath, and to compare the main characteristics of the Fe-W alloys deposition process occurring in the $\mathrm{Fe}(\mathrm{III})$ - and $\mathrm{Fe}(\mathrm{II})$ - based solutions.

\section{Experimental}

Fe-W alloys were electrodeposited from citrate and glycolate-citrate baths containing $\mathrm{Fe}$ (II) or $\mathrm{Fe}$ (III) sulfate as a source of iron. The composition of the baths and their lab codes are presented in Table I, and chemicals used have been of analytical grade (A.R.). All solutions were prepared by regular dissolving of components. However, the equilibrium of species during preparation of citrate $\mathrm{Fe}$ (III)based solution was setting within longer period of time. The initial C3 solution was brown, but it changes the color to green after a few hours of electrodeposition. So, in order to obtain reproducible results from this bath, electrodeposition has been carried out after $500 \mathrm{C} / \mathrm{cm}^{2}$ passed through the solution. The influence of electrolyte run on the electrodeposition of $\mathrm{Fe}-\mathrm{W}, \underline{18}$ zinc and nickel, 30 chromium $\underline{11}$ were also detected and it is important parameter to be taken into account.

Adjustment of $\mathrm{pH}$ was made by adding $\mathrm{NaOH}$ or $\mathrm{H}_{2} \mathrm{SO}_{4}$. Electrodeposition of thin films was performed in a typical three-electrode cell. The pure copper sheet with $4.5 \mathrm{~cm}^{2}$ area was used as a working electrode. Platinized titanium was used as a counter electrode, and saturated $\mathrm{Ag} / \mathrm{AgCl}$ was used as reference electrode. All values of electrode potentials are presented against this reference electrode. Prior electrodeposition, the samples were polished, degreased and activated in $2 \mathrm{M}$ sulphuric acid for 1 minute. In order to improve adhesion to the substrate a thin Ni seed-layer was deposited at a cathodic current density of $20 \mathrm{~mA} / \mathrm{cm}^{2}$ for 1 minute from $1 \mathrm{M}$ nickel chloride solution in $2.2 \mathrm{M}$ hydrochloric acid. Polarization curves were recorded at $20^{\circ} \mathrm{C}$ and $65^{\circ} \mathrm{C}$, and $5 \mathrm{mV} / \mathrm{s}$ scan rate using AUTOLAB system (GPES software), and later were corrected for ohmic drop that was determined using FRA 4.9 software. The current efficiency (CE) of the alloys and resulted thickness of the coatings were determined based on Faraday's law, as was described elsewhere.32 The thickness of electrodeposited Fe-W coatings 
was $\sim 5 \mu \mathrm{m}$. The thickness of several samples was measured on cross-section in order to confirm the values calculated based on CE. Partial current densities for the corresponding metal were calculated based on the composition and mass of the coating according to following equation:

$$
j_{M}=\frac{n_{M} \omega_{M} F}{\mu_{M} t}
$$

here $j_{M}$ is the partial current density for the corresponding metal " $M$ " (in A/cm²); $n_{M}$ is the number of electrons involved in the charge transfer reaction, $\omega_{M}$ is the weight of metal " $M$ ' $\left(\mathrm{g} / \mathrm{cm}^{2}\right), F$ is Faraday constant, $\mu_{M}$ is the atomic mass of metal " $M$ " $(\mathrm{g} / \mathrm{mol}), t$ is the electrodeposition time (s).

The stability of solutions was estimated based on the calculation of species distribution in the electrolyte, taking into account more than 40 simultaneously occurring equilibrium reactions. For this purpose, a system of equations was solved using adopted Maple6 (Waterloo Maple Software and University of Waterloo). The set of equations was based on: (i) the equilibrium constants for all compounds added to or formed in the solutions: acids deprotonation, $\underline{33}, \underline{34}$ iron hydrolysis,, 35.36 polymerization of tungstate, $\underline{37}$ glycolate complexes with $\mathrm{Fe}$ and $\mathrm{W}_{\underline{38}} \underline{41}$ and metal complexes with citrate; $\underline{42}-\underline{45}$ (ii) the mass balance equations [ $]_{\text {tot }}=\sum\left[J_{\left.n^{+/}-i\right]}\right.$ for all forms in the equilibrium mixture; (iii) the charge balance $\sum n\left[\mathrm{Cat}_{n}{ }^{+}\right]=\sum n\left[A n_{n}{ }^{-}\right]$, where "Cat" and "An" denote cation and anion, respectively. In our study, glycolic and citric acids are considered as mono- and four protonated, respectively.

The composition and microstructure of the deposited alloys were identified by scanning electron microscope (SEM) using Hitachi TM3000 instrument. The chemical composition of the alloys was determined with the energy dispersive X-ray spectroscopy (EDS) analysis tool attached to the SEM. The crystallographic structure and phase composition of the obtained coatings was studied by means of Rigaku MiniFlex II diffractometer with Cu Ka radiation $(\lambda=1.54183 \AA$ ) operated at $30 \mathrm{kV}$ and $30 \mathrm{~mA}$. The mean crystallite size was estimated based on the peak width and position using Scherrer's equation.

\section{Results and Discussion}

Thermodynamics of Fe(III)-based electrolytes for Fe-W alloys electrodeposition

The development of stable $\mathrm{Fe}$ (III)-based plating bath consists in the selection of suitable complexing agents able to prevent formation of sparingly soluble iron hydroxides. In this work we focused on glycolic acid, which might be considered as an alternative complexing agent to conventional baths for Fe-W alloys deposition. In order to evaluate the influence of glycolic acid on the bath stability the thermodynamic calculations were performed considering the influence of the solution content on the concentration of "free" $\mathrm{Fe}^{3+}$ ions.

The maximum concentration of $\mathrm{Fe}^{3+}$ ions in the electrolyte is limited by the solubility product of $\mathrm{Fe}(\mathrm{OH})_{3}$. In each complex system, the concentration of particular component depends on the whole composition of the solution. Therefore, it is essential to take into account the ionic strength of solution. Using the second approximation of Debye-Hückel theory and considering the ionic strength of investigated electrolytes $\mathrm{I} \approx 2 \mathrm{M}$, the solubility product of freshly formed $\mathrm{Fe}(\mathrm{OH})_{3}$ was estimated as $\mathrm{LI}=2 \mathrm{MFe}(\mathrm{OH})_{3}=7.4 \cdot 10-36 \mathrm{LFe}(\mathrm{OH}) 3 \mathrm{I}=2 \mathrm{M}=7.4 \cdot 10-36$.

The distribution of species as a function of $\mathrm{pH}$ was calculated, and for some ions, it is presented in Figure 1. On the Figures $1 \mathrm{a}, \underline{1 \mathrm{~b}}$ the line marked as $\left[\mathrm{Fe}^{3+}\right]_{\text {sat }}$ is a maximum thermodynamic concentration of $\mathrm{Fe}^{3+}$ ions in the solution, and it was calculated as a function of $\mathrm{pH}$ based on $\mathrm{Fe}(\mathrm{OH})_{3}$ solubility product using following expression: 


$$
\left[\mathrm{Fe}^{3+}\right]_{s a t}=\frac{L_{\mathrm{Fe}(\mathrm{OH})_{3}}}{K_{\mathrm{H}_{2} \mathrm{O}}^{3}} \cdot\left[H^{+}\right]^{3}
$$

here $\mathrm{KH}_{2} \mathrm{OKH} 2 \mathrm{O}$ is the ionization constant of water.

Evidently, the electrolyte is stable and no precipitates are noticed if $\left[\mathrm{Fe}^{3+}\right]<\left[\mathrm{Fe}^{3+}\right]_{\text {sat }}$, i.e. the electrolyte is considered as thermodynamically stable below the line $\left[\mathrm{Fe}^{3+}\right]_{\text {sat. }}$.

As it is shown in Figure 1a, $\mathrm{Fe}$ (III)-based glycolate solutions are stable in the acidic media only, while citrate solutions without adding of $\mathrm{Na}_{2} \mathrm{WO}_{4}$ are stable in the wide range of $\mathrm{pH}$. However, considering the electrodeposition of Fe-W alloys with relatively high amount of tungsten, the electrodeposition should be carried out from neutral or weak alkaline solutions.2.11.15 In the presence of $\mathrm{Na}_{2} \mathrm{WO}_{4}$ formation of complexes with $\mathrm{WO}_{4}{ }^{2-}$ occurs as well, and ligands are redistributed between $\mathrm{Fe}(\mathrm{III})$ and tungstate, therefore the concentration of "free" $\mathrm{Fe}^{3+}$ ions increases and thus the stability of solutions decreases sufficiently (Figure 1b).

In citrate solutions at $\mathrm{pH}<6$ complex $\left(\mathrm{WO}_{4}\right)_{2}(\mathrm{HCit}) \mathrm{H}^{3}{ }_{4}$ predominates, while at $\mathrm{pH}$ above 6 the concentration of $\mathrm{W}$-citrate complexes decreases and $\mathrm{WO}_{4^{2-}}$ dominates (Figure $1 \mathrm{C}$ ). Hence, at pH above 6 the Fe-citrate complexes are formed and the concentration of free $\mathrm{Fe}^{3+}$ ions decreases respectively. Glycolic acid is the weaker complexing agent for $\mathrm{Fe}^{3+}$ than citrate. Despite the concentration of glycolic acid several times exceeded the concentration of metals, the stability line of glycolate bath is situated closer to $\left[\mathrm{Fe}^{3+}\right]_{\text {sat. }}$. Therefore, in the pure glycolate solutions $\left[\mathrm{Fe}^{3+}\right] \approx\left[\mathrm{Fe}^{3+}\right]_{\text {sat }}$ and these electrolytes can be stable only for a while, due to kinetic peculiarities of hydrolysis in the complex solutions, i.e. glycolate solutions are in the thermodynamically metastable state.

It was assumed, that addition of citric acid to glycolate bath should stabilize electrolyte due to formation of $\mathrm{Fe}(\mathrm{III})$ and $\mathrm{W}(\mathrm{VI})$ complexes with citrate and glycolate ones. Tungsten forms stronger complexes with glycolate $\left(\mathrm{WO}_{2} \mathrm{Gly}^{2}{ }_{2}\right)$ than with citrate, and in the glycolate-citrate solutions tungsten complexes dominate over the citrate, while $\mathrm{Fe}(\mathrm{III})$ ions are mainly in the citrate complexes (see Figures $1 \mathrm{~b}$ and 1c), that indeed stabilizes glycolate-citrate solution. The formation of W-glycolate complex over the Wcitrate is expected to have a significant influence on the electrodeposition process, resulting in easier deposition of metallic ions on the cathode from the complex with smaller molecular volume.

For electrodeposition of the alloys we used $\mathrm{pH}$ 6.5-6.7, considering the electrodeposition of Fe-W alloys with high tungsten content. At this $\mathrm{pH}$ the concentration of $\mathrm{W}(\mathrm{VI})$-glycolate complexes in GC3 bath and $\mathrm{W}(\mathrm{VI})$-citrate complexes in $\mathrm{C} 3$ bath begins to decrease and concentration of "free" $\mathrm{WO}_{4^{2-}}$ increases, therefore less amount of free $\mathrm{Fe}^{3+}$ ions are present in the solution, leading to the higher stability. It is also worth to notice, that thermodynamic calculations certainly represent a good approach to understanding the bath stability, however they do not consider kinetic of the process.

\section{Cathodic polarization study}

Complex formation of $\mathrm{Fe}(\mathrm{II}), \mathrm{Fe}(\mathrm{III})$ and $\mathrm{W}(\mathrm{VI})$ with citrate and glycolate results in sufficient shifts of Nernst equilibrium potentials in the investigated solutions especially for $\mathrm{Fe}$ (III) reduction to iron (see Table II). Polarization curves were recorded in order to estimate the electrodeposition conditions for Fe-W alloys (Figure 2). Also, cathodic polarization curves were obtained for pure Fe deposition in order to specify the role of $\mathrm{W}(\mathrm{VI})$ in electrodeposition of Fe-W alloy. Electrodeposition of pure iron was carried out from electrolytes contained the same components as listed in Table I, but without sodium tungstate. The plateau on the polarization curves in the range of potentials -0.7 to $-1.1 \mathrm{~V}$ is observed for Fe deposition, while for $\mathrm{Fe}-\mathrm{W}$ it was observed in the narrower potential range. Potentiostatic depositions corresponding to potential range $-0.7 \mathrm{~V} \div-0.9 \mathrm{~V}$ have been carried out for 30 minutes from investigated electrolytes. It was determined that metals do not deposit in the corresponding potential 
ranges. The similar plateau obtained for Fe-W electrodeposition is described by Gamburg.18 It might be attributed to the water decomposition, reduction of dissolved oxygen and partial reducing of iron compounds.

As it is seen from Figure 2, the decreasing in polarization is observed after adding sodium tungstate into solution, while pure iron deposition occurs at relatively higher polarizations from all investigated solutions. The sufficient increase of cathodic current density for Fe-W alloy is noticed at potentials more negative than $-0.9 \mathrm{~V}$ (the ohmic drop was taken into account) attesting the start of deposition. The given current increases with the temperature growth, which in its turn influence on the potential shift to the smaller polarizations.

The partial current densities obtained for $\mathrm{Fe}$ and Fe-W deposition were calculated and are shown in Table III. It is seen that at $20^{\circ} \mathrm{C}$ the co-deposition of tungsten with iron results in higher partial current densities of $\mathrm{Fe}$ and decreased partial current of the side reaction, as compared to pure Fe deposition. Whereas at $65^{\circ} \mathrm{C}$ the partial current for $\mathrm{W}$ increases, but partial current densities for Fe and side reaction are decreased. Moreover, the general trend is observed that above the total current density $20 \mathrm{~mA} / \mathrm{cm}^{2}$ the partial current density of the side reaction (which is mainly the hydrogen evolution) significantly increases, influencing on the current efficiency and morphology of the obtained coatings, which will be discussed below.

\section{Composition, morphology and structure of Fe-W Coatings}

In order to determine the optimum conditions for Fe-W electrodeposition, the temperature was varied between $20^{\circ} \mathrm{C}$ and $65^{\circ} \mathrm{C}$ and the cathodic current density from 5 to $50 \mathrm{~mA} / \mathrm{cm}^{2}$, while the concentration of electrolyte components and $\mathrm{pH}$ were kept constant. The poor adhesion of $\mathrm{Fe}-\mathrm{W}$ coatings on copper substrate was observed, apparently due to the difference between crystallographic structures of these materials.46 The adhesion was improved essentially by the electrodeposition of nickel seed-layer prior the deposition of alloys.

The tungsten content in Fe-W alloys obtained from the glycolate-citrate baths depends on the temperature, whereas for alloys obtained from the citrate baths it is less dependent (Figure 3). Markedly, Fe-W coatings electrodeposited at room temperature from glycolate-citrate based solutions have lower tungsten content than obtained from citrate solutions. Probably, it is due to slightly lower concentration of "free" WO ${ }_{4}{ }^{2-}$ ions in the GC3 bath than in C3 electrolyte (Figure 1c), that result in lower partial current density for tungsten codeposition from GC3 solution at room temperature.

EDS analysis data show that electrodeposited Fe-W coatings contain a significant percentage of oxygen, which is higher than that for other tungsten alloys with iron group metals.g However, the oxygen content does not correlate with current density, temperature or alloy composition. This fact attests that obtained oxygen content is linked probably only with oxidation of surface by water or air. The results obtained in Ref. $\underline{9}$ on oxygen content in tungsten alloys with $\mathrm{Co}, \mathrm{Ni}$ and Fe confirm that only thin surface layer contains high amount of oxygen, whereas practically no oxygen was determined in the deeper layers of coatings.

The values of CE attained at various temperatures $\left(20-65^{\circ} \mathrm{C}\right)$ for the different Fe-W solutions are presented in Figure 4. CE obtained for $\mathrm{Fe}$ (II)-based solutions are lower than that for $\mathrm{Fe}(\mathrm{III})$-based solutions especially for GC2 ( 15\%) and it is even lower than that for citrate C2 bath. It is worth to notice, that the CE calculation for $\mathrm{Fe}(\mathrm{II})$-based electrolytes is rather questionable, because of the lack of the control of iron ions oxidation. Therefore, we used only Fe(II)-based freshly prepared baths. It is expected, that with accumulation of $\mathrm{Fe}^{3+}$ ions in electroplating bath the $\mathrm{CE}$ can increase by $\sim 10 \% .12$ In fact, the usage of $\mathrm{Fe}(\mathrm{III})$-based solutions warrants the constant composition of solution because eliminates the chemical oxidation of $\mathrm{Fe}(\mathrm{II})$ compounds by dissolved oxygen and oxometalates.19 The highest values of current efficiency were attained in the all investigated solutions at cathodic current 
density of $20 \mathrm{~mA} / \mathrm{cm}^{2}$. As it is seen, the nature of solution is a key-factor governing CE, whereas variations of $C E$ with temperature is rather weak and $C E$ changes in the range of about $\pm 10 \%$ for each solution if temperature exceeds $30^{\circ} \mathrm{C}$. The lowest values of $\mathrm{CE}$ were obtained for $\mathrm{Fe}(\mathrm{II})$-based solutions. The presence of glycolic acid contributed to the significant increase of CE up to $60-70 \%$ for Fe-W alloys deposition from GC3 electrolyte in comparison with other electrolytes. Such high CE has been not noticed for Fe-W alloys deposition earlier. This result seems very appealing, since the value of CE for Fe alloys deposition usually does not exceed $40 \%$ and $20 \%$ in $\mathrm{Fe}$ (II)- and $\mathrm{Fe}$ (III)-based electrolytes respectively. 14.18 On the other hand, increased values of $\mathrm{CE}$ for $\mathrm{Fe}(\mathrm{III})$-based solutions are defined also by lower weigh of electrochemical equivalent for $\mathrm{Fe}$ in comparison with $\mathrm{Fe}(\mathrm{II})$-based solutions. Therefore, it is not adequate to compare CE values obtained from solutions where particular metal is present in the different oxidation states. In the given case, a comparison of deposition rates should be more appropriate in order to assess the efficacy of electroplating baths. These data are presented in Figure 5. As it is seen, the alloy deposition rates for GC3 bath is high enough especially at elevated temperatures, whereas for other solutions this parameter is ranged from 0.12 to 0.15 $\mu \mathrm{m} / \mathrm{cm}^{1}$.

Another important characteristic of electrodeposited alloys is the surface morphology. The SEM images of $\mathrm{Fe}-\mathrm{W}$ coatings deposited at different temperatures from investigated electrolytes are presented in Figure 6. The surface of electrodeposited coatings is smooth (roughness of the coatings was ca. 100-150 nm dependently on $\mathrm{W}$ content) and typically contains micro-spheres. The temperature has effect on the surface morphology: increase in the temperature up to $65^{\circ} \mathrm{C}$ results in obtaining of smoother coatings from C2 and GC2 solutions, while it does not influence essentially on the morphology of coatings electrodeposited from the GC3 solution. Also, high internal stress which can appear due to the hydrogen evolution leads to the cracks propagation for coatings deposited at room temperature and relatively high current densities. Remarkably, the alloys obtained from $\mathrm{Fe}$ (III)based glycolate-citrate electrolyte are more compact and with less stress even electrodeposited at room temperature.

Thus, influence of the current density on morphology of Fe-W alloys deposited from GC3 electrolyte is shown in Figure 7. Fe-W alloys deposited at $5 \mathrm{~mA} / \mathrm{cm}^{2}$ have holes resulted from hydrogen evolution on the whole surface. With increase in the current density the nucleation rate increases and crystallite refinement takes place, thus the surface becomes smoother. However, at cathodic current densities higher than $30 \mathrm{~mA} / \mathrm{cm}^{2}$, the surface becomes cracked due to the progressive increase in hydrogen evolution.

The alloys investigation by X-ray diffraction reveals that the shape of XRD patterns for Fe-W alloys obtained at the same temperature depends on the content of tungsten regardless of the solution type used for electrodeposition. The typical XRD patterns of Fe-W alloys electrodeposited at $20^{\circ} \mathrm{C}$ are presented in Figure 8. In general, the broadening of XRD peaks with increase in W content in the alloy is obtained, as it was observed for the electrodeposited W-and Mo- containing alloys with iron group metals.9.10.47 In order to understand Fe-W coatings structure, pure Fe also was electrodeposited from similar bath composition to GC3, but without tungstate. It can be seen, that a well-defined polycrystalline structure of body-centered $\mathrm{Fe}$ is obtained for pure electrodeposited Fe. The shift of four peaks, characteristic to pure iron to the lower 2 theta angles in the case of alloy having 11 at.\% of W can be observed. Indeed, calculations using Vegard's equation 48 show the increase in average closest distance between two adjacent atoms, which is probably caused by the substitution of $\mathrm{Fe}$ atoms by the bigger $\mathrm{W}$ atoms in the lattice. It might be supported by the fact that solubility limit of $\mathrm{W}$ in bcc Fe is $\sim 14$ at.\%.49 Hence, the formation of solid solution of $\mathrm{W}$ in $\mathrm{Fe}$ is expected at $\mathrm{W}$ content up to this value. When content of tungsten equal or exceeds 14 at.\%, only one broad peak appears which is typical for "amorphous-like" structure, that is associated with decrease in crystallite size from 30 to $\sim 5 \mathrm{~nm}$. This amount of $\mathrm{W}$ in the alloy can be considered as determining for transition from the nanocrystalline to 
amorphous-like structure of Fe-W coatings at room temperature. Moreover, this transition at rather low tungsten content is characteristic for tungsten alloy deposits obtained at room temperature due to specific nucleation process. $\underline{50}$

\section{Conclusions}

Fe-W alloys have been successfully electrodeposited from newly developed $\mathrm{Fe}$ (III)-based electrolyte contained both citric and glycolic acid as complexing agents and the main characteristics of the deposition process were compared to the ones obtained using Fe(II) baths. The simulation of electrolytes stability shows that the investigated $\mathrm{Fe}(\mathrm{III})$-based glycolate-citrate electrolyte is thermodynamically stable in the neutral and weakly alkaline solutions due to peculiarities of $\mathrm{Fe}$ (III) and $\mathrm{W}(\mathrm{VI})$ complexes distribution in the concurrent presence of citrate and glycolate ions. In these solutions $\mathrm{W}(\mathrm{VI})$ forms dominantly complexes with glycolate ions, whereas $\mathrm{Fe}(\mathrm{III})$ with citrates. The current efficiency of the electrodeposition process occurring in Fe(III) glycolate-citrate bath reaches up to 60$70 \%$, which is much higher than that obtained in the citrate baths or any other previously reported ironbased electrolytes. Compact and smooth coatings with high W content are obtained at elevated temperatures and low current densities, since at these conditions the partial current of side reaction is small. The increased content of tungsten in Fe-W alloys results in the decrease in values of crystallite size from 30 to $\sim 5 \mathrm{~nm}$.

Thus, elaborated environmentally friendly electrolyte has high importance due to the possibility to obtain good quality Fe-W coatings from Fe(III)-based solution with tunable W content, high current efficiency and deposition rate; also it may be considered for electrodeposition of other Fe based alloys.

\section{Tables}

\begin{tabular}{|c|c|c|c|c|}
\hline \multirow[b]{2}{*}{ Components } & \multicolumn{4}{|c|}{ Composition of electrolytes, mol/L } \\
\hline & $\begin{array}{c}\text { Cit-Fe(II) } \\
\text { C2 }\end{array}$ & $\begin{array}{c}\text { Cit-Fe(III) } \\
\text { C3 }\end{array}$ & $\begin{array}{c}\text { Glyco-Cit-Fe(II) } \\
\text { GC2 }\end{array}$ & $\begin{array}{c}\text { Glyco-Cit-Fe(III) } \\
\text { GC3 }\end{array}$ \\
\hline $\mathrm{Na}_{2} \mathrm{WO}_{4} \cdot 2 \mathrm{H}_{2} \mathrm{O}$ & 0.40 & 0.40 & 0.40 & 0.40 \\
\hline $\mathrm{FeSO}_{4} \cdot 7 \mathrm{H}_{2} \mathrm{O}$ & 0.20 & - & 0.20 & - \\
\hline $\mathrm{Fe}_{2}\left(\mathrm{SO}_{4}\right)_{3} \cdot \mathrm{H}_{2} \mathrm{O}$ & - & 0.10 & - & 0.10 \\
\hline $\mathrm{C}_{6} \mathrm{H}_{8} \mathrm{O}_{7} \cdot \mathrm{H}_{2} \mathrm{O}$ (citric acid) & 0.20 & 0.20 & 0.30 & 0.30 \\
\hline $\mathrm{Na}_{3} \mathrm{C}_{6} \mathrm{H}_{5} \mathrm{O}_{7} \cdot 2 \mathrm{H}_{2} \mathrm{O}$ (tri-sodium citrate) & 0.45 & 0.45 & - & - \\
\hline $\mathrm{C}_{2} \mathrm{H}_{4} \mathrm{O}_{3}$ (glycolic acid) & - & - & 1.00 & 1.00 \\
\hline
\end{tabular}

Table II. Standard reduction potentials, $E^{0}$, and Nernst equilibrium potentials, $E_{N}$, in the investigated solutions at $\mathrm{pH} 6.7$ for reduction of ferric/ferrous and tungstate ions (vs. NHE). Values of the equilibrium concentration of "free" $\mathrm{Fe}^{3+}, \mathrm{Fe}^{2+}$ and $\mathrm{WO}_{4}{ }^{2-}$ ions were taken from Fig. 1. Compositions of solutions and their lab codes are shown in Table I.

\begin{tabular}{cccrr} 
& & \multicolumn{3}{c}{$\mathrm{E}_{\mathrm{N}}, \mathrm{V}$} \\
\cline { 3 - 5 } Electrochemical reaction & $\mathrm{E}^{0}, \mathrm{~V}$ & $\mathrm{C} 2$ & $\mathrm{C} 3$ & $\mathrm{GC} 2$ \\
\hline$F e^{3+}+3 e^{-}=F e$ & -0.036 & & -0.294 & -0.266 \\
$F e^{2+}+2 e^{-}=F e$ & -0.440 & -0.596 & -0.553 & -0.494
\end{tabular}


Table III. Partial current densities for metals (Fe and W) and side reaction obtained in the GC3 electrolyte without and with sodium tungstate.

\begin{tabular}{|c|c|c|c|c|c|c|c|c|}
\hline \multirow[b]{3}{*}{$\mathrm{T}^{\circ} \mathrm{C}$} & \multirow[b]{3}{*}{$-\mathrm{j}, \mathrm{mA} / \mathrm{cm}^{2}$ total } & \multicolumn{3}{|c|}{$\mathrm{Fe}$} & \multicolumn{4}{|c|}{$\mathrm{Fe}-\mathrm{W}$} \\
\hline & & \multicolumn{2}{|c|}{-jpartial, $\mathrm{mA} / \mathrm{cm}^{2}$} & \multirow[b]{2}{*}{ E, V } & \multicolumn{3}{|c|}{-jpartial, $\mathrm{mA} / \mathrm{cm}^{2}$} & \multirow[b]{2}{*}{ E, V } \\
\hline & & $\mathrm{Fe}$ & Side reaction & & $\mathrm{Fe}$ & $\mathrm{w}$ & Side reaction & \\
\hline \multirow[t]{2}{*}{20} & 15 & 2 & 13 & -1.25 & 7 & 2 & 6 & -1.20 \\
\hline & 40 & 5 & 35 & -1.41 & 9 & 3 & 28 & -1.35 \\
\hline \multirow[t]{2}{*}{65} & 15 & 8 & 7 & -1.17 & 7 & 4 & 4 & -1.07 \\
\hline & 40 & 14 & 26 & -1.26 & 17 & 12 & 11 & -1.19 \\
\hline
\end{tabular}

\section{Figures}
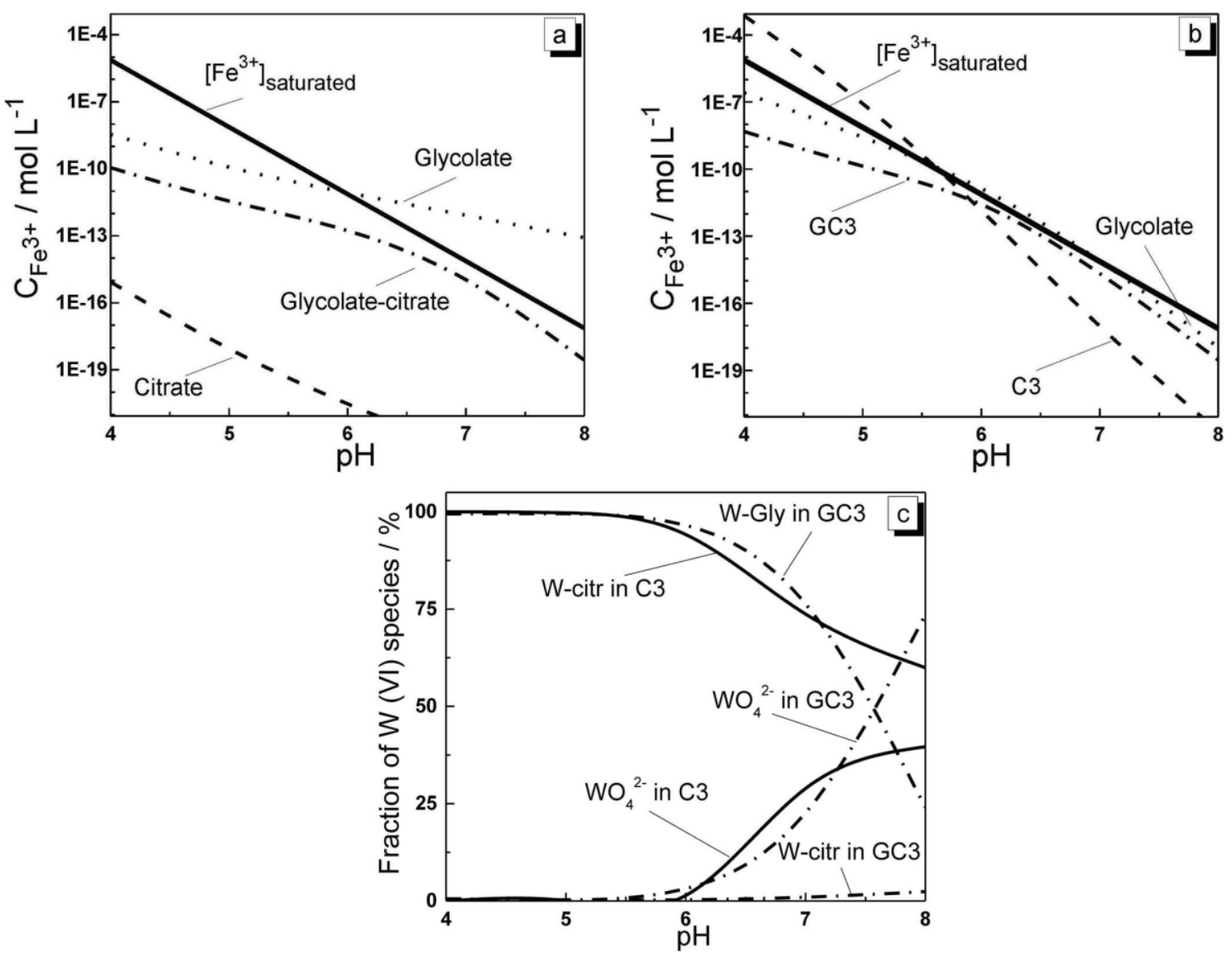

Figure 1. Calculated concentrations of some species as a function of $\mathrm{pH}$ in the $\mathrm{Fe}(\mathrm{III})$-based solutions: (a) $\mathrm{Fe} 3+$ without sodium tungstate; (b) Fe3+ with sodium tungstate; (c) fractions of W(VI) species: free WO42and complexes with citrates and glycolates; "W-Cit" means the sum $\left[(\mathrm{WO} 4)(\mathrm{HCit}) \mathrm{H}^{4}\right]+\left[(\mathrm{WO} 4) 2(\mathrm{HCit}) \mathrm{H} 4^{3}\right.$ -] and "W-Gly" means [WO2Gly2-2]. The types of electrolytes are market next to the corresponding curve. Compositions of electrolytes are given in Table I. 

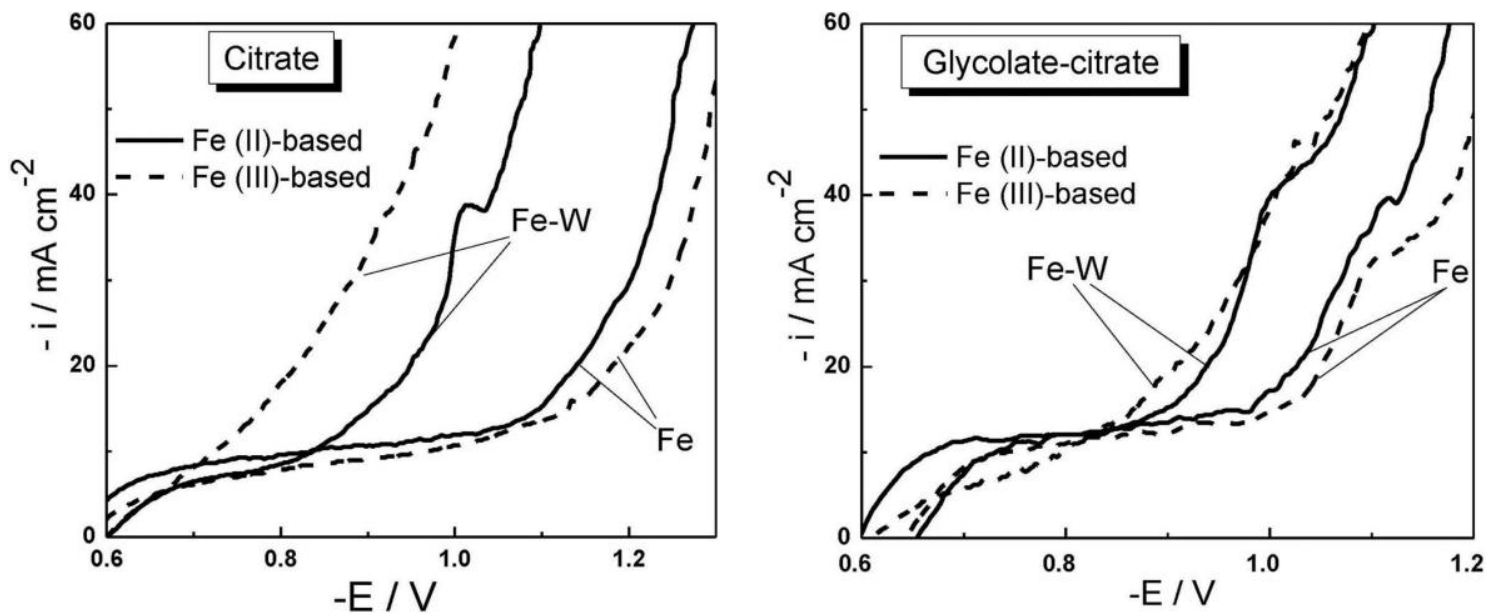

Figure 2. Cathodic polarization curves for Fe and Fe-W alloy deposition from citrate and glycolate-citrate electrolytes obtained at $65^{\circ} \mathrm{C}$.

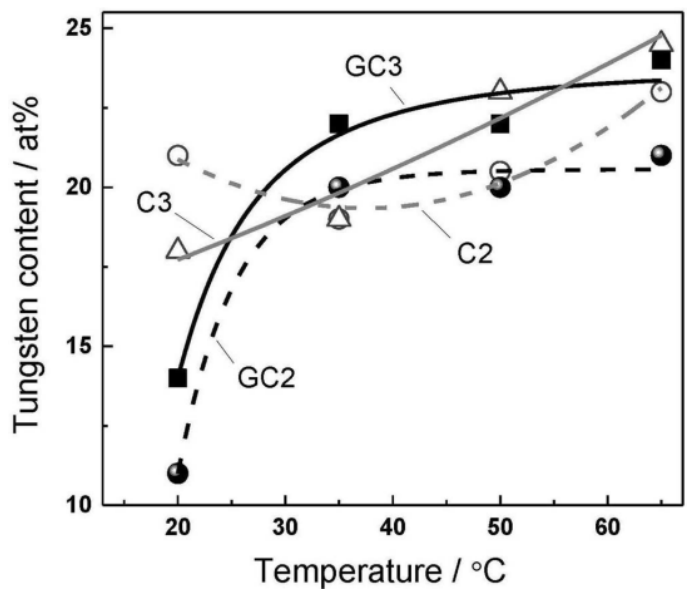

Figure 3. Temperature influence on tungsten content in the Fe-W alloys electrodeposited from the investigated solutions at cathodic current density $20 \mathrm{~mA} / \mathrm{cm} 2$. Lab codes and composition of solutions are indicated in Table I.

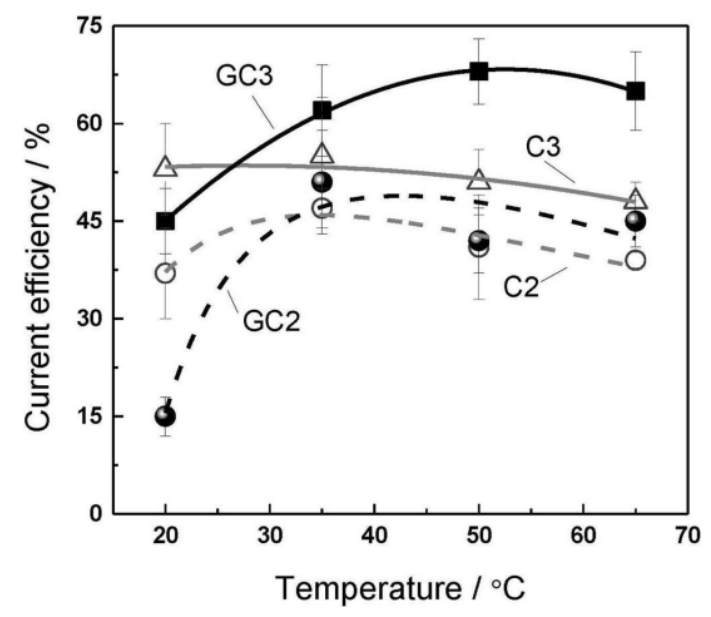

Figure 4. Temperature influence on current efficiency for $\mathrm{Fe}-\mathrm{W}$ electrodeposition in the investigated solutions at cathodic current density $20 \mathrm{~mA} / \mathrm{cm} 2$. Lab codes and composition of solutions are indicated in Table I. 


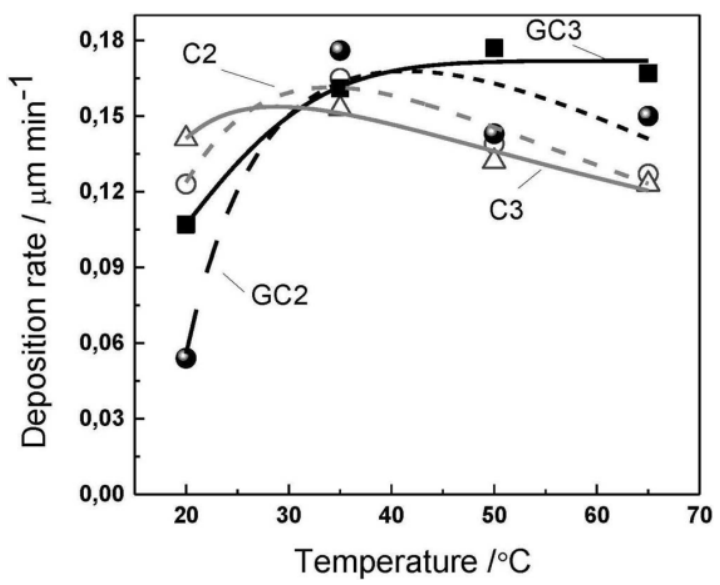

Figure 5. Temperature influence on Fe-W coatings deposition rates from studied solutions at cathodic current density $20 \mathrm{~mA} / \mathrm{cm} 2$. Lab codes and composition of solutions are indicated in Table I.

C2

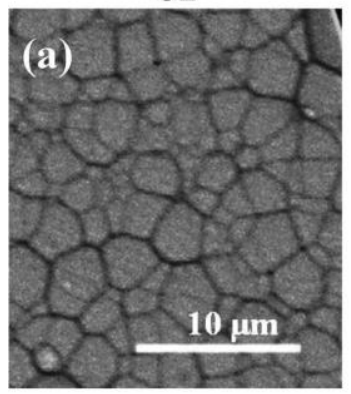

(e)

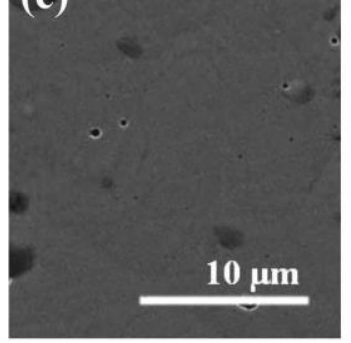

C3
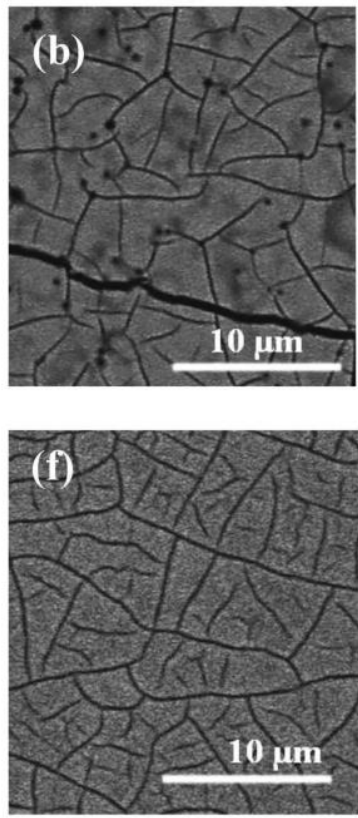

GC2
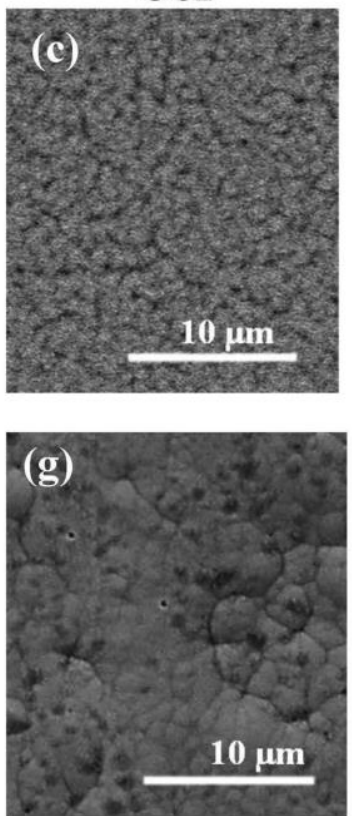

GC3
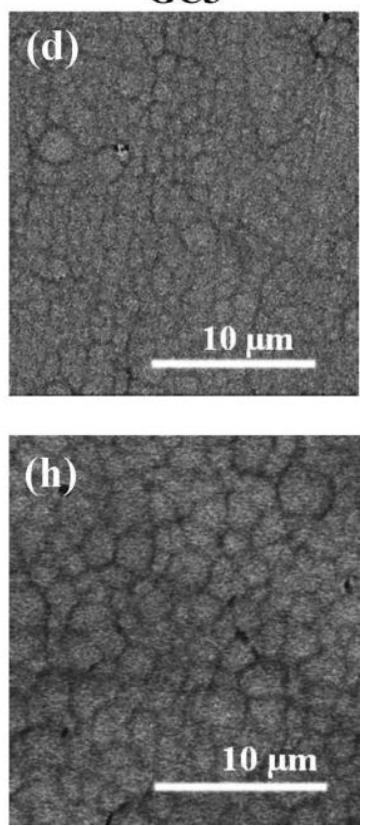

Figure 6. SEM images of Fe-W alloys obtained at $-20 \mathrm{~mA} / \mathrm{cm} 2$ from different electrolytes at $20 \cdot \mathrm{C}(\mathrm{a}, \mathrm{b}$, $c, d)$ and $65^{\circ} \mathrm{C}(\mathrm{e}, \mathrm{f}, \mathrm{g}, \mathrm{h})$.
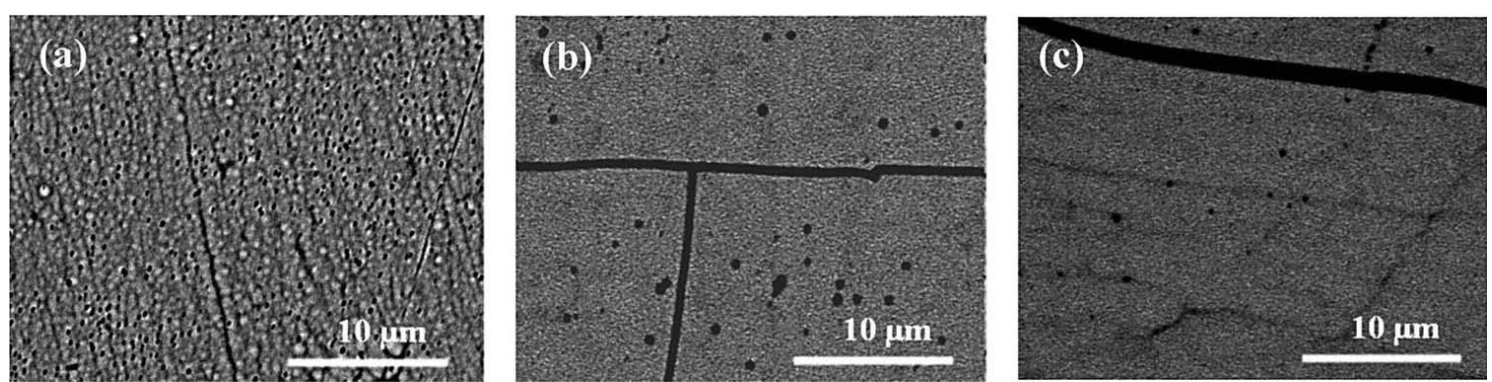

Figure 7. SEM images of Fe-W alloys obtained from GC3 electrolyte at $20{ }^{\circ} \mathrm{C}$ at the following current densities: (a) $5 \mathrm{~mA} / \mathrm{cm} 2$; (b) $30 \mathrm{~mA} / \mathrm{cm}^{2}$; (c) $40 \mathrm{~mA} / \mathrm{cm} 2$. 


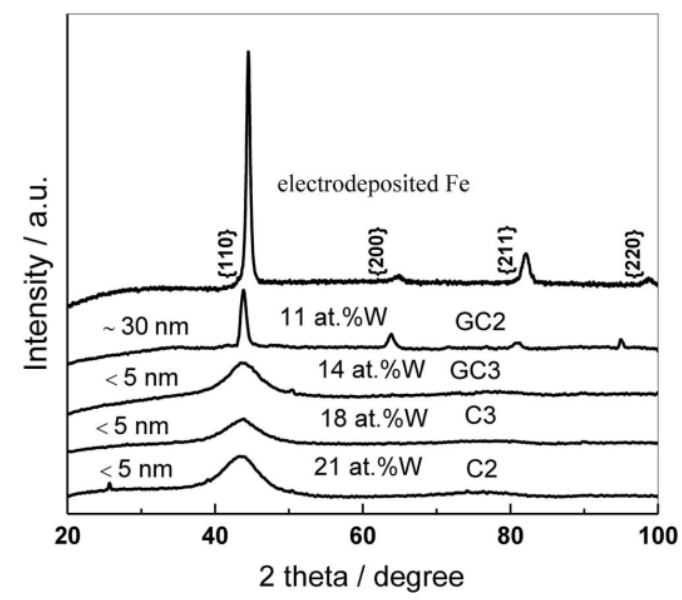

Figure 8. Representative XRD patterns of Fe-W alloys deposited from different electrolytes at $20{ }^{\circ} \mathrm{C}$ and $20 \mathrm{~mA} / \mathrm{cm} 2$. The peaks were identified based on 06-0696 (Fe) ASTM Cards. Estimated values of crystallite size are shown next to the corresponding pattern.

\section{Acknowledgments}

The authors acknowledge funding from H2020 SELECTA project (642642), from the Research Council of Lithuania (MIP-031/2014) and Moldavian national project (15.817.02.05A).

\section{References}

1. S. Wang, C. Zeng, Y. Ling, J. Wang, and G. Xu, Surf. Coat. Technol., 286, 36 (2016).

2. N. Tsyntsaru, A. Dikusar, H. Cesiulis, J. P. Celis, Z. Bobanova, S. Sidel'nikova, S.Belevskii,Y.Yaponttseva,O. Bersirova,andV. Kublanovskii,Powder Metall. Met C+, 48, 419 (2009).

3. S. Changwei, Ye Mengchao, Z. Linxing, H. Jianping, Li Junmin, and G. Junming, Surf. Rev. Lett., 23, 1550100 (2015).

4. N.Thangaraj,K.Tamilarasan,andD.Sasikumar,Indian J.Pure Appl. Phys.,52,395 (2014).

5. M. V. Ved, T. O. Nenastina, V. V. Shtefan, T. M. Bairachna, and M. D. Sakhnenko, Mater. Sci., 44, 840 (2008).

6. C. Tharamani, P. Beera, V. Jayaram, N. Begum, and S. Mayanna, Appl. Surf. Sci., 253, 2031 (2006).

7. L. Holt and R. Black, J. Electrochem. Soc., 82(1), 205 (1942).

8. G. Croopnik, (1985).

9. M. Donten, J. Solid State Electrochem., 3, 87 (1999).

10. N. Tsyntsaru, H. Cesiulis, M. Donten, J. Sort, E. Pellicer, and E. J. Podlaha-Murphy, Surf. Eng. Appl. Electrochem., 48, 491 (2012). 
11. M. Donten, Z. Stojek, and H. Cesiulis, Electrochim. Acta, 45, 3389 (2000).

12. M. Lietzke and M. Holt, J. Electrochem. Soc., 94, 252 (1948).

13. N. Eliaz and E. Gileadi, in Modern Aspects of Electrochemistry, Vol.42, C. Vayenas, Editor, p. 191, Springer, New York (2008).

14. Zh. Bobanova, A. Dikusar, H. Cesiulis, J. -P. Celis, I. Tsyntsaru, and I. Prosycevas, Russ. J. Electrochem., 45, 895 (2009).

15. V. Vasauskas, J. Padgurskas, R. Rukuiza, H. Cesiulis, J. -P. Celis, D. Milcius, and I. Prosycevas, Mekhanika, 21, 1392 (2008).

16. O. Younes, L. Zhu, Y. Rosenberg, Y. Shacham-Diamand, and E. Gileadi, Langmuir,

17, 8270 (2001). 17. N. Tsyntsaru, Zh. Bobanova, D. Kroitoru, V. Cheban, G. Poshtaru, and A. Dikusar, Surf. Eng. Appl. Electrochem., 46, 538 (2010).

18. Y. Gamburg, E. Zakharov, and G. Goryunov, Russ. J. Electrochem., 37, 670 (2001).

19. G. Yar-Mukhamedova, M. Ved, N. Sakhnenko, A. Karakurkchi, and I. Yermolenko, Appl. Surf. Sci., 383,346 (2016).

20. L. Chang, Z. Wang, S. Shi, and W. Liu, J. Alloys Compd., 509, 1501 (2011).

21. A. Afshar, A. Dolati, and M Ghorbani, Mater. Chem. Phys., 77, 352 (2002).

22. J. Weiss, Ber. Bunsenges. Phys. Chem., 73(2), 131 (1969).

23. B. Morgan and O. Lahav, Chemosphere, 68, 2080 (2007).

24. G. Krishnamurti and P. Huang, Clays Clay Miner., 39, 28 (1991).

25. M.Izaki,inModernElectroplating,5th.ed.,M.SchlesingerandM.Paunovic,Editors, John Wiley \& Sons, New Jersey (2010).

26. R. Renuka and S. Ramamurthy, Bull. Electrochem., 13(12), 456 (1997).

27. V. C. Kieling, Surf. Coat. Technol., 96(2-3), 135 (1997).

28. D. Park, B. Yoo, S. Kelcher, and N. Myung, Electrochim. Acta, 51, 2523 (2006).

29. S. Yao and M. Kowaka, J. Metal Finish. Soc. Japan., 39(11), 736 (1988).

30. Y.GamburgandG.Zangari,Theoryandpracticeofmetalelectrodeposition,Springer, New York Dordrecht Heidelberg London (2011).

31. N. Mandich and D. Snyder, in Modern Electroplating, 5th. ed., M. Schlesinger and M. Paunovic, Editors, John Wiley \& Sons, New Jersey (2010).

32. P. Padhakrishnamurty, Bull. Electrochem., 15(7-8), 252 (1999). 
33. L.SillenandA.Martel,Stability constantsofmetal-ioncomplexes,Vol.2,Chemical Society, London (1971).

34. E. Bulemela, L. Trevani, and P. Tremaine, J. Solution Chem., 34, 769 (2005).

35. A. Stefansson, Environ. Sci. Technol., 41, 6117 (2007).

36. R. Lemire, U. Berner, C. Musikas, D. A. Palmer, P. Taylor, and O. Tochiyama, in Chemical thermodynamics of iron, Vol13a, J. Perrone, Editor, Elsevier, Amsterdam (2013).

37. J. Aveston, Inorg. Chem., 3, 981 (1964).

38. A. Martell and R. Smith, Critical stability constants, Vol3, 495 p., Plenum Press, New York (1977).

39. R. Portanova, Pure Appl. Chem., 75, 495 (2003).

40. S. Muthu Priya and S. Shailaja, OSR J. Appl. Chem., 8, 1 (2015).

41. M. Aldeir, M. Ramos, and V. Gil, Canadian J. Chem., 64, 827 (1987).

42. C. Timberlake, J. Chem. Soc., 0, 5078 (1964).

43. M. Andre, N. Silva, X. Kong, M. Parkin, R. Cammack, and R. Hider, Dalton Trans., 40, 8616 (2009).

44. I. Gautier-Luneau, C. Merle, D. Phanon, C. Lebrun, F. Biaso, G. Serratrice, and J. L. Pierre, Chem.Eur. J., 11, 2207 (2005).

45. J. Cruywagen, L. Kr"uger, and E. Rohwer, J. Chem. Soc. Dalton Trans., 7, 1727 (1991).

46. M. Donten, T. Gromulski, and Z. Stojek, J. Alloys Compd., 279, 272 (1998).

47. M. Lu and C. Chien, J. Appl. Phys., 67, 5787 (1990).

48. N.Tsyntsaru,H.Cesiulis,E.Pellicer,J. -P.Celis,andJ.Sort,Electrochim.Acta,104, 94 (2013).

49. E. Lassner and W. Schubert, Tungsten: Properties, Chemistry, Technology of the Element Alloys and Chemical Compounds, 434 p., Kluwer Academic / Plenum Publishers, New York (1999).

50. E. Vernickaite, N. Tsyntsaru, and H. Cesiulis, Trans. IMF, 94, 313 (2016). 